\title{
The inner core of the serum response element mediates both the rapid induction and subsequent repression of c-fos transcription following serum stimulation
}

\author{
Victor M. Rivera, Morgan Sheng, and Michael E. Greenberg ${ }^{1}$ \\ Department of Microbiology and Molecular Genetics, Harvard Medical School, Boston, Massachusetts 02115 USA
}

\begin{abstract}
Serum stimulation of quiescent fibroblasts results in a dramatic increase in c-fos transcription that peaks by 15 min and is then rapidly repressed to basal levels within $60 \mathrm{~min}$. Using a nuclear run-on assay to follow directly the kinetics of transcription of mutant c-fos constructs, we demonstrate that the serum response element (SRE) is the site of regulation of both the induction and repression events. This is indicated by the ability of the SRE to mediate c-fos kinetics of induced transcription when fused to a heterologous gene and in the absence of a recognizable TATA element. Functions of the inner core and the outer palindromic arms of the SRE have been determined by mutagenesis. The 14-bp inner core binds the serum response factor (SRF) and is, itself, sufficient to mediate both the induction and shutoff of serum-stimulated transcription. Therefore, SRF and any other factors that regulate the transient kinetics of $c$-fos transcription require no more than these $\mathbf{1 4}$ nucleotides to function. The palindromic outer arms of the SRE stabilize the binding of SRF and thereby enhance the transcriptional response to serum. Autoregulation by the $c$-fos gene product is not affected by the direct interaction of Fos/Jun complexes with the c-fos promoter and is likely to be mediated by either a novel function of the Fos protein or by an effect of Fos on the expression of another gene.
\end{abstract}

[Key Words: Transcriptional regulation; c-fos; transcriptional repression; immediate early genes; serum response element]

Received July 24, 1989; revised version accepted November 28, 1989.

The transduction of a mitogenic signal from the cell membrane to the nucleus results in the rapid transcriptional activation of a set of cellular immediate early genes. The best characterized member of this group of 50-100 genes (Cochran et al. 1983; Greenberg and Ziff 1984; Lau and Nathans 1985, 1987; Lim et al. 1987; Almendral et al. 1988) is the c-fos proto-oncogene. Available evidence suggests that the Fos protein propagates the mitogenic signal by initiating a cascade of secondary gene expression that leads to DNA replication and subsequent cell division. This view is supported by the finding that $\mathrm{c}$-fos encodes a nuclear protein that binds to an AP-1 site (-TGAGTCA-; Angel et al. 1987; Lee et al. 1987) in a heterodimeric transcription complex with the product of another proto-oncogene, c-iun (Halazonetis et al. 1988; Kouzarides and Ziff 1988; Nakabeppu et al. 1988; Rauscher et al. 1988). The Fos-Jun complex has been shown to regulate the expression of genes bearing an AP-1 element in their upstream control region (Chiu et al. 1988; Lucibello et al. 1988; Schonthal et al. 1988).

Considering the central role that c-fos plays in the transmission of the mitogenic signal, defining the mech-

${ }^{1}$ Corresponding author. anism by which its expression is controlled is critical to the understanding of normal cellular growth and oncogenesis. A common feature of the regulation of the immediate early genes is that they are transcriptionally activated within minutes of growth factor stimulation without the requirement for new protein synthesis (Cochran et al. 1983; Lau and Nathans 1985, 1987; Greenberg et al. 1986; Almendral et al. 1988). This suggests that the mitogenic signal is transduced via the post-translational modification of pre-existing factors. Another hallmark of many of the immediate early genes is the transient nature of their activation /Greenberg and Ziff 1984; Lau and Nathans 1985, 1987; Almendral et al. 1988). In the case of c-fos, the rapid induction of transcription is soon followed by a shutoff event that returns transcription to quiescent levels within $60 \mathrm{~min}$ after stimulation (Greenberg and Ziff 1984). In contrast to the activation phase, the shutoff of transcription of the immediate early genes is dependent on new protein synthesis, suggesting the involvement of a labile or newly synthesized repressor protein (Greenberg et al. 1986; Lau and Nathans 1987).

Mutational analysis of the c-fos upstream region has identified a serum response element (SRE), which is re- 
quired for c-fos induction by serum (Gilman et al. 1986; Treisman 1986; Greenberg et al. 1987) and is sufficient to confer serum induction upon a heterologous gene (Siegfried and Ziff 1989). This 20-bp dyad symmetry element, centered $310 \mathrm{bp}$ upstream of the mRNA initiation site, binds a nuclear protein, the serum response factor (SRF; Gilman et al. 1986; Prywes and Roeder 1987; Treisman 1986; Greenberg et al. 1987). Binding of SRF to the SRE appears to be essential for growth factor activation of c-fos transcription (Fisch et al. 1987; Greenberg et al. 1987; Treisman 1987; Gilman 1988; Sheng et al. 1988). In addition to SRF, several other nuclear proteins interact with the upstream region of the c-fos gene (Gilman et al. 1986; Fisch et al. 1987; Hayes et al. 1987). Two of these proteins have a molecular weight of 62,000. p62/MAPF1 interacts with the SRE (Ryan et al. 1989; Walsh 1989), and p62 interacts with an SRE/SRF complex (Shaw et al. 1989b). Fos-Jun complexes have also been suggested to bind to AP-1-like elements within the c-fos promoter (Schonthal et al. 1989), and several recent studies have indicated that the Fos protein, itself, may be involved in the down-regulation of c-fos transcription (Sassone-Corsi et al. 1988; Schonthal et al. 1988, 1989; Wilson and Treisman 1988).

Despite the considerable progress in identifying factors that interact with its promoter in vitro, little is known about the actual mechanism by which growth factors cause the activation and subsequent repression of c-fos transcription. One scheme postulates that SRF acts as the activator, whereas the Fos protein, itself, functions as the repressor. In this model, SRF binds to the SRE, whereas Fos, possibly complexed with c-Jun, interacts with one of several downstream DNA sequences with similarity to the AP-1 binding site. An alternative model is that the role of Fos in the down-regulation process is indirect. For instance, Fos could activate the expression of another gene(s) that encodes a transcription factor important for the down-regulation event. To distinguish among these and other possibilities, we carried out experiments to identify the critical sequence elements that mediate c-fos transcriptional shutoff.

Using a nuclear run-on assay to follow directly the kinetics of transcription, we show that the SRE is sufficient to mediate both the rapid induction and repression of serum-stimulated transcription. Mutagenesis of the SRE demonstrates that the 14-bp inner core of this element is the site of regulation of both events. The outer palindromic arms of the SRE stabilize the binding of SRF and thereby enhance the transcriptional response to serum. The autoregulatory function of Fos in this SREdependent shutoff event is either indirect or requires accessory factors to promote a Fos/SRE interaction.

\section{Results}

The kinetics of transcription of the human c-fos gene stably introduced into NIH-3T3 cells parallel those of the endogenous mouse gene

We have employed a nuclear run-on transcription assay to identify the DNA sequences required for the repres- sion of c-fos transcription that follows its activation by serum. The use of this assay to study the mechanism of c-fos down-regulation has several advantages. Most importantly, it measures transcription directly rather than relying on the analysis of cytoplasmic RNA. We found that two factors can obscure visualization of the transcription shutoff event: (1) experimental manipulations that cause alterations in the half-life of the c-fos mRNA, such as the transfection of a large amount of DNA (Shyu et al. 1989), and (2) the use of chimeric gene constructs with stable reporter transcripts (Fisch et al. 1989a; Shyu et al. 1989; Siegfried and Ziff 1989). Furthermore, if sequences critical for transcriptional down-regulation lie within the body of the c-fos gene, measurement of cytoplasmic mRNA levels would not distinguish those effects on transcriptional shutoff from those on message stability. Several modifications of the standard run-on transcription protocol have been introduced to allow its use in the study of transfected genes (see Methods).

We find that the human c-fos gene, stably transfected into $3 \mathrm{~T} 3$ cells, is activated and repressed following serum stimulation with kinetics nearly identical to those seen for the endogenous mouse gene. Transcription from $\mathrm{pF} 4$, which contains the entire human c-fos gene, including 750 nucleotides of its upstream regulatory sequence, is rapidly and transiently induced, reaching peak levels $15 \mathrm{~min}$ after stimulation and returning to near basal levels by $60 \mathrm{~min}$ (Fig. $1 \mathrm{~A} ; \mathrm{C}-\mathrm{FOS}^{\mathrm{H}}$ ). Transcripts from the human gene $\left(\mathrm{c}-f_{0} s^{\mathrm{H}}\right)$ are distinguished from those of the endogenous mouse gene (c$\left.f o s^{M}\right)$ by the use of a probe corresponding to the second intron of the human gene. The human c-fos intron sequence has diverged sufficiently from the mouse so that it does not hybridize significantly to the endogenous c-fos transcripts, as shown in a control cell line transfected with vector DNA instead of the human c-fos gene (Fig. 1A; pUC). Transient activation of endogenous cfos ${ }^{\mathrm{M}}$ transcription is detected in the parent $3 \mathrm{~T} 3$ cells if a mouse c-fos cDNA probe is used (Fig. 1A; 3T3). In contrast to c-fos, serum stimulation does not induce mouse $\alpha$-tubulin gene transcription, thus providing an internal control for the normalization of nuclear RNA levels at each time point. The wild-type M13-derived vector, into which the c-fos and tubulin probes are cloned, itself, shows no cross-hybridization with ${ }^{32} \mathrm{P}$-labeled run-on transcripts. This indicates that the transcripts detected by the probes are due to hybridization with the insert and not the M13 vector sequences.

To verify that the c-fos run-on transcripts produced from the transfected genes are initiating correctly, the start site of the human c-fos message was determined by RNase protection. Properly initiated transcripts from the human and mouse c-fos genes protect 296- and 65-bp fragments, respectively, of a human c-fos antisense probe (Treisman 1985; Sheng et al. 1988). Figure 1B shows that RNA from a cell line containing the human c-fos gene $\left(\mathrm{C}-\mathrm{FOS}^{\mathrm{H}}\right)$ protects the appropriate sized fragments upon serum stimulation, indicating that proper transcriptional initiation has occurred.

Thus, the use of an intron probe specific to the human 


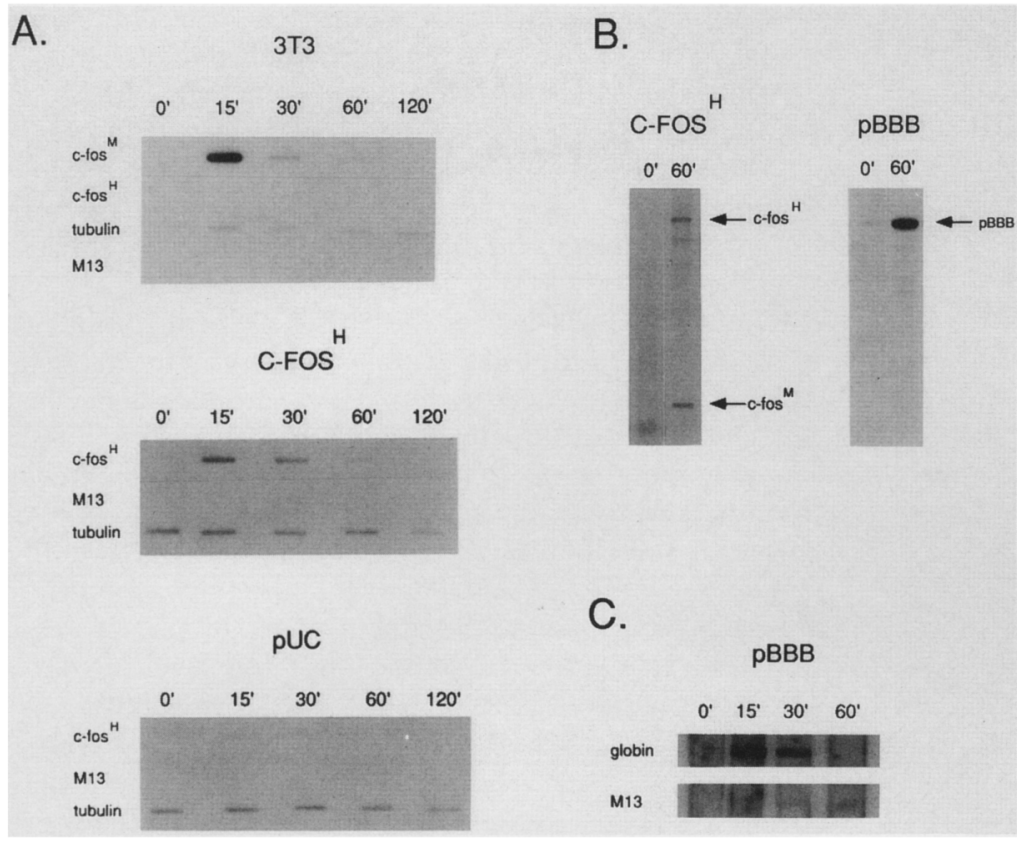
The fos promoter is sufficient to direct the rapid and transient transcriptional response to serum. Nuclear run-on transcription analysis of $3 \mathrm{~T} 3$ cells stably transfected with plasmid $\mathrm{pBBB}$ was done and analyzed as described in $A$. The following DNA probes were used to detect ${ }^{32}$ P-labeled RNA: (globin) M13mp9 3 -globin; (M13) M13mp18.

c-fos gene permits accurate measurement of the kinetics of properly initiated transcription from a transfected c-fos construct by the nuclear run-on assay. Because the kinetics of expression from the transfected human c-fos gene mimic those seen for the endogenous gene, the run-on assay can be applied to mutant constructs to identify the sequences required for c-fos induction and repression.

\section{The SRE is sufficient to direct rapid transcriptional induction and repression}

Upon transfection into $3 \mathrm{~T} 3$ cells, gene constructs containing the minimal elements required for correct growth factor regulation of c-fos expression would be expected to direct transcription with the same kinetics as seen for the wild-type c-fos gene. In contrast, constructs lacking a cis-acting element required for transcriptional shutoff would show either prolonged expression or a constant level of expression before and after stimulation.

When the region -711 to -13 of the c-fos promoter is fused to the rabbit $\beta$-globin gene, a gene that is not normally expressed in fibroblast cells, transcription is rapidly induced and repressed following serum stimulation (Fig. 1C; pBBB). RNase protection analysis indicates that induced transcription from this cell line reflects an increase in properly initiated transcripts (Fig. 1B). This demonstrates that sequences within the body of the c-fos gene are not required for wild-type kinetics of transcription. Rather, all the critical DNA determinants are included within the 700-bp upstream control region.

The SRE, at -310 , is essential for serum induction; however, its involvement in the subsequent shutoff of
Figure 1. (A) The human c-fos gene stably transfected into $3 \mathrm{~T} 3$ cells is transcribed with kinetics that parallel those of the endogenous mouse gene following serum stimulation. In nuclear run-on transcription analysis of untransfected NIH-3T3 cells or cells stably transfected with plasmid pF4 $\left(\mathrm{C}-F^{\mathrm{H}} \mathrm{S}^{\mathrm{H}}\right)$ or carrier DNA (pUC), nuclei were harvested from quiescent cells that had been stimulated with $20 \%$ fetal bovine serum for the indicated time. Transcripts were elongated in the presence of $\left[\alpha^{-32} \mathrm{P}\right] \mathrm{UTP}$ by the in vitro nuclear run-on assay and hybridized with nylon filters that were spotted with the following DNA probes: (c-fos $\left.{ }^{M}\right)$ pGEMfos3; (c$f s^{\mathbf{H}}$ ) M13HPPA; (tubulin) M13MATA; (M13), M13Goril. (B) Transcripts from the human c-fos and $\mathrm{c}$-fos/ $\beta$-globin fusion genes stably introduced into $3 \mathrm{~T} 3$ cells initiate at the proper start site. Quiescent 3T3 cells stably transfected with pF711 (C$F S^{H}$ ) or pBBB were stimulated with $20 \%$ fetal bovine serum for $60 \mathrm{~min}$, or left unstimulated (0). Cytoplasmic RNA was isolated, and transcripts corresponding to the pBBB fusion gene (Shyu et al. 1989) and the c-fos ${ }^{\mathrm{M}}$ and $\mathrm{c}-$ fos $^{\mathrm{H}}$ genes (Treisman 1985; Sheng et al. 1988) were detected by the RNase protection assay. The positions of correctly initiated transcription has not been addressed. Instead, it has been suggested that an adjacent AP-1-like element at -296 (-TGCGTCA-), which may bind Fos-Jun complexes (Piette and Yaniv 1987; Schonthal et al. 1989), is necessary for the down-regulation event (Wilson and Treisman 1988; Schonthal et al. 1989|. pF222, which contains the c-fos gene and 222 nucleotides upstream of the mRNA start site, shows little or no induction upon serum stimulation (Fig. 2A; Treisman 1985; Greenberg et al. 1987). When a 61-bp portion of the c-fos promoter, containing both the SRE and AP-1-like elements, is inserted at -222 of $\mathrm{pF} 222$, transcription is induced and rapidly repressed with wild-type kinetics [Fig. 2A; pF222(332-272)]. However, when the SRE alone is inserted at -222 , proper kinetics of induction and repression are retained (Fig. $2 A_{;}$pF222SRE), indicating that the AP-1-like site adjacent to the SRE is not required for transcriptional repression. pF222(332-272) $\Delta 1$ contains a single-base-pair deletion in the SRE that leaves the AP-1-like element intact. This deletion abolishes the ability of the element to bind SRF and mediate the serum response (Fig. 2A; Greenberg et al. 1987). This indicates that the AP-1-like site at -296 is not sufficient to mediate serum induction in 3T3 cells. RNase protection analysis of cytoplasmic RNA from the above cell lines confirms that each cell line was serum-stimulated, as demonstrated by the increased expression of the endogenous c-fos ${ }^{\mathrm{M}}$ gene and that the $\mathrm{c}-f o s^{\mathrm{H}}$ run-on transcripts detected in stimulated cells originated from the proper mRNA start site (Fig. 2B).

Next, we examined the role of sequences downstream of -222 in the shutoff of transcription. Included in this region is an element at -60 (-TGACGTTT-) that has 


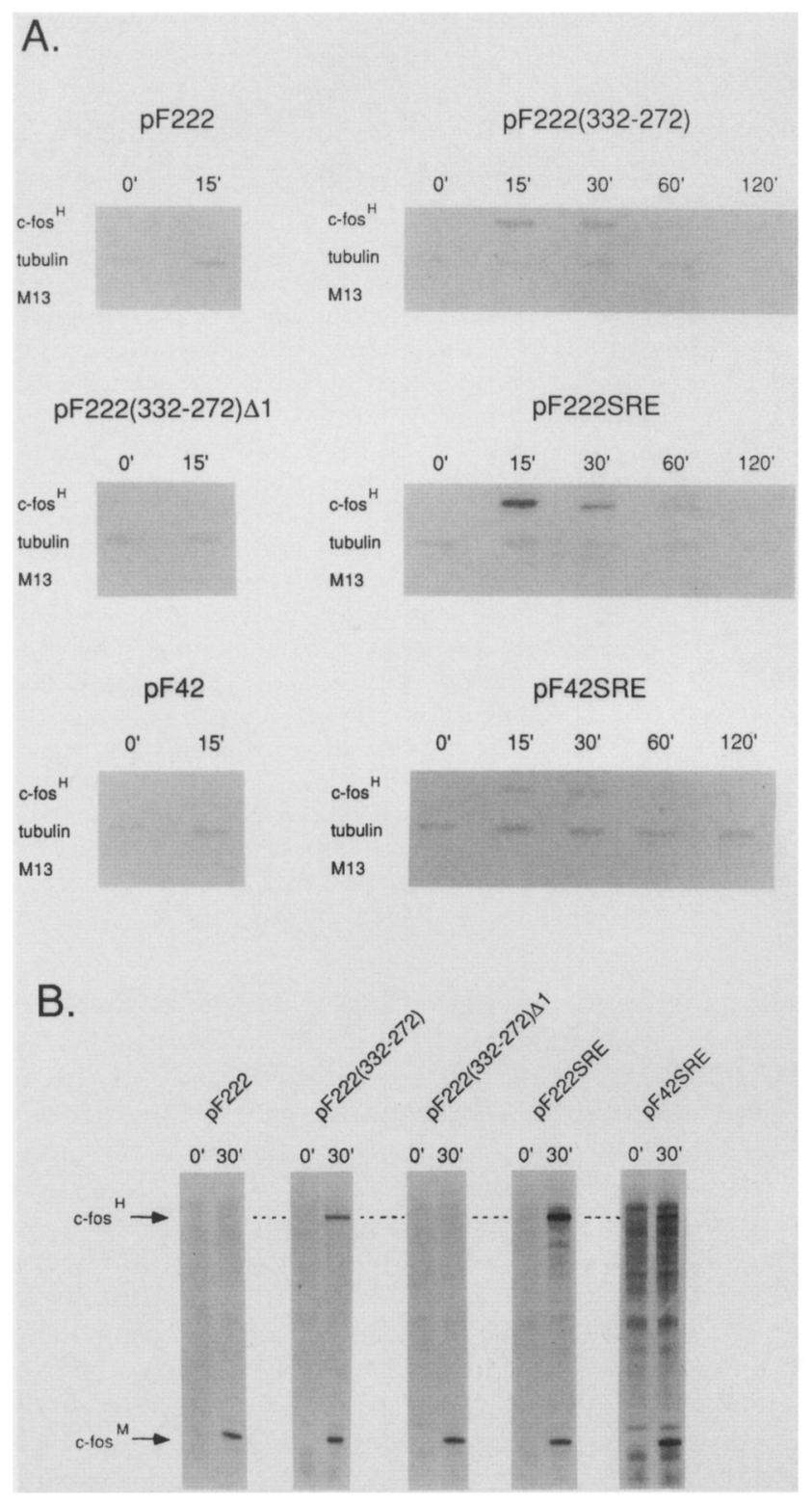

Figure 2. (A) The SRE confers wild-type kinetics of induction and repression of transcription upon a minimal c-fos promoter following serum stimulation. 3T3 cells stably transfected with the indicated plasmids were analyzed by the nuclear run-on assay, as described in Fig. 1A. The following DNA probes were

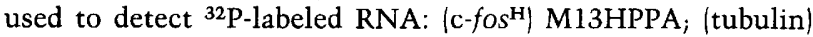
M13MATA; (M13) M13Goril. (B) Transcripts from human c-fos promoter deletion constructs initiate at the proper start site. Cytoplasmic RNA from serum stimulated ( $30 \mathrm{~min})$ or unstimulated $(0 \mathrm{~min})$ cells lines, described in $A$, was analyzed by the RNase protection assay. Correctly initiated transcripts produced by the $\mathrm{c}-f \circ s^{\mathrm{H}}$ and $\mathrm{c}-f \circ s^{\mathrm{M}}$ genes are indicated by arrows.

been suggested to play a role in the down-regulation event (Schonthal et al. 1989) on the basis of its ability to bind Fos-Jun complexes in vitro (Schonthal et al. 1989; M.E. Greenberg, unpubl.).pF42, which contains the c-fos gene and only 42 nucleotides upstream of the mRNA start site, is not responsive to serum (Fig. 2A). However, insertion of the SRE at -42 is sufficient to restore properly initiated transcription (Fig. 2B; pF42SRE) with wild type kinetics of activation and repression (Fig. 2A). Therefore, the -60 element and all other elements upstream of -42 , with the exception of the SRE, are not essential for the shutoff of transcription following senum stimulation.

We determined whether the SRE alone was sufficient to mediate c-fos kinetics of transcription by inserting a single copy of the SRE in front of a heterologous gene. $\mathrm{p} \beta$-globin contains the entire human $\beta$-globin gene and 48 nucleotides of upstream sequence. Figure $3 \mathrm{~A}$ shows that the insertion of the SRE at -48 of the $\beta$-globin promoter ( $p \beta$-globin/SRE) is sufficient to confer both rapid transcriptional induction and repression upon the normally unresponsive $p \beta$-globin gene. RNase protection analysis confirms that the increased level of transcription conferred by the SRE is due to an increase in properly initiated transcripts (Fig. 3B).

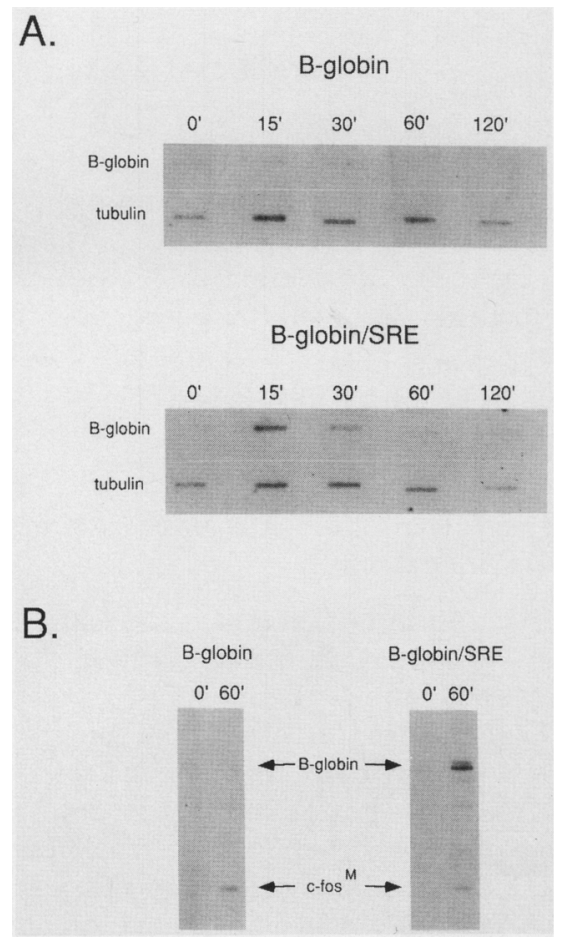

Figure 3. The SRE is sufficient to confer c-fos kinetics of transcriptional induction and repression on a heterologous promoter following serum stimulation. 3T3 cells stably transfected with the indicated plasmids were analyzed by the nuclear run-on and RNase protection assays. $(A)$ The nuclear run-on assay was performed as described in Fig. $1 \mathrm{~A}$, using the following DNA probes to detect ${ }^{32} \mathrm{P}$-labeled RNA: ( $\beta$-globin) M13mp9 $\beta$-globin; (tubulin) M13MATA. (B) The RNase protection assay was used to detect transcripts initiated from the $\beta$ globin and endogenous c-fos ${ }^{\mathrm{M}}$ genes. Properly intiated transcripts are indicated by arrows. Transcripts initiating from the start site within exon 1 of $\beta$-globin/SRE protect a 142 -bp fragment of a $\beta$-globin antisense probe (Siegfried and Ziff 1989). 
The $c$-fos TATA element is not required for the rapid and transient response to serum

All constructs that we have shown to direct proper c-fos transcriptional regulation contain both the SRE and a TATA element. The possibility that the TATA element may be required to direct serum-stimulated transcription of $\mathrm{c}-f \circ S$ is suggested by the previous finding that activation of c-fos transcription by the adenovirus E1A protein is dependent on the presence of the TATA box (Simon et al. 1990). Furthermore, mutational analysis of both yeast (Chen and Struhl 1988) and mammalian TATA boxes (Simon et al. 1988) suggests the existence of functionally distinct TATA elements.

Transcription from pFC700, which contains the c-fos promoter fused to the chloramphenicol acetyltransferase (CAT) gene, confirms that the c-fos promoter is sufficient to confer rapid and transient kinetics of serum-induced transcription on a heterologous gene (Fig. 4C). We find that point mutants (Fig. 4A), in which the c-fos TATA sequence has been changed to that of the SV40 early promoter (pFCpm1) or knocked out (pFCpm2), are not only still responsive to serum but are also rapidly repressed following stimulation (Fig. 4B,C). This is best illustrated in Figure 4B, which shows a plot of the CAT signals from duplicate run-on experiments that were quantitated and normalized to the tubulin signals. We conclude from these experiments that in contrast to E1A induction of c-fos (Simon et al. 1990), appropriate serum induction and repression of transcription does not require the presence of a particular TATA element.

Support for these conclusions also comes from the analysis of two other immediate early genes, Krox-20 (Chavrier et al. 1989) and zif/268 (Christy et al. 1988). These genes are transcribed with kinetics identical to c-fos and contain SRE-like elements, yet neither has a TATA box similar to that of c-fos. Furthermore, other serum-inducible heterologous genes have also been described that contain the c-fos promoter and a distinct TATA element (Mohun et al. 1987; Siegfried and Ziff 1989).

Though we have not determined the transcription
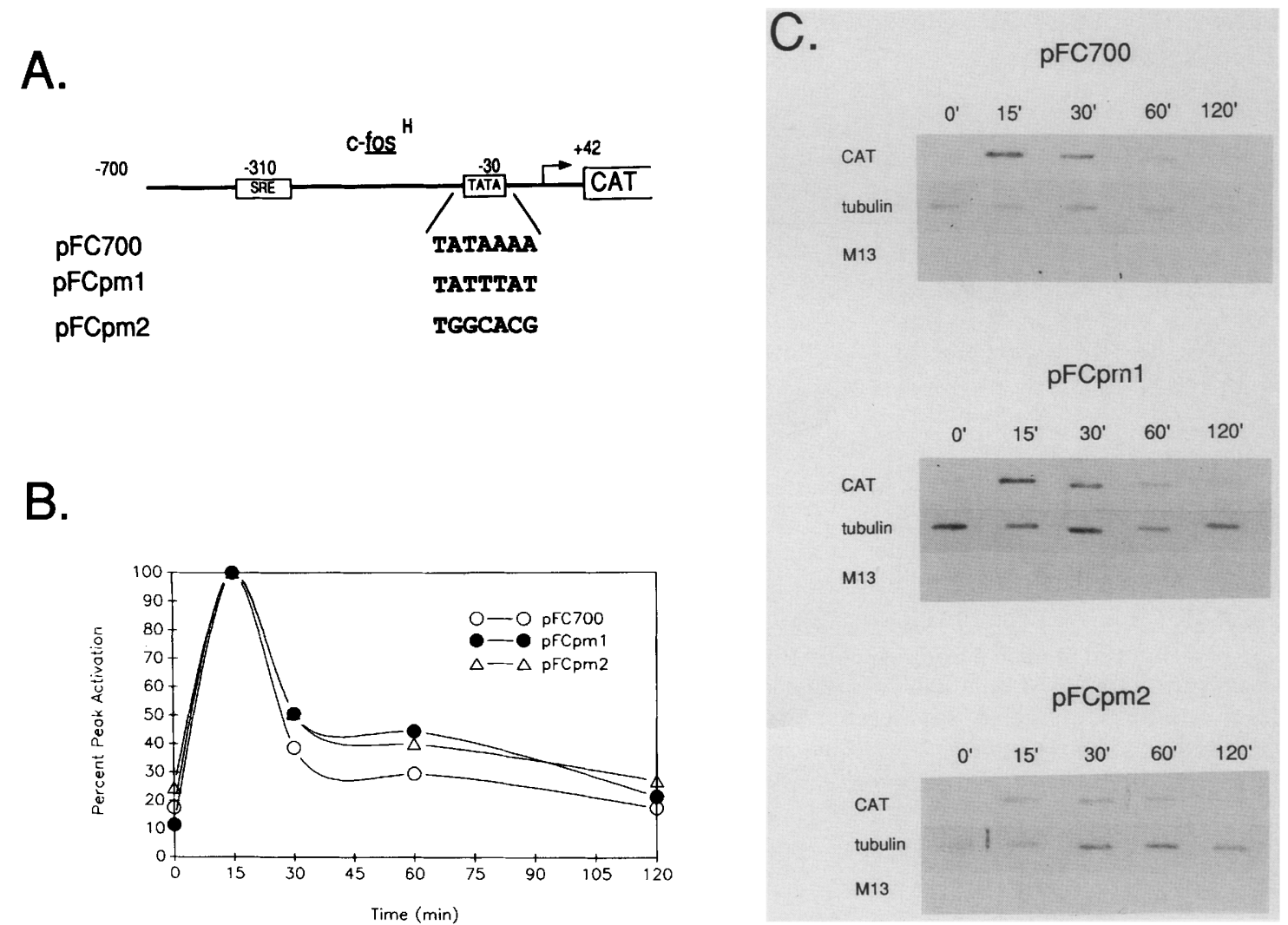

Figure 4. Mutation of the c-fos TATA box does not significantly alter the magnitude or kinetics of transcriptional activation and

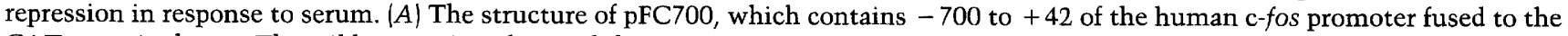
CAT gene, is shown. The wild-type TATA box and the mutant TATA boxes introduced into pFC700 by site-directed mutagenesis are shown below. (B) A plot of the levels of transcription of pFC700, pFCpml, and pFCpm2 at various time points after serum stimulation. Transcripts hybridizing to the CAT and tubulin plasmids were quantitated from the appropriate exposure by laser densitometry. The CAT signal in each time point was normalized to that of tubulin and plotted as the percentage of peak induction at 15 min. The averaged results of duplicate experiments are shown. (C) $3 \mathrm{~T} 3$ cells stably transfected with the indicated plasmids were analyzed by the nuclear run-on assay, as described in Fig. 1A. The following DNA probes were used to detect ${ }^{32}$ P-labeled RNA: (CAT) M13CATA; (tubulin) M13MATA; (M13) M13Goril. The CAT probe does not show any detectable hybridization to transcripts from cell lines that do not contain the c-fos/CAT fusion genes (data not shown), demonstrating the specificity of this probe. 
start sites of these constructs, the start sites of pFC700 and pFCpm 1 have been mapped previously to the appropriate position following stimulation by serum (Fisch et al. 1987) and cAMP (Fisch et al. 1989b), respectively. On the other hand, pFCpm2 may behave as the Krox-20 gene, which also lacks a TATA box and therefore exhibits heterogeneous start sites of transcription but is rapidly and transiently induced in response to serum (Chavrier et al. 1989).

The inner core of the SRE is sufficient to bind SRF and mediate induction and repression

The results described above strongly suggest that the regulation of both the induction and repression events takes place at the SRE. The 20-bp SRE may be divided into two regions: an inner core that contains the sequence CCATATTAGG-, and outer arms that contain a region of extended dyad symmetry (Fig. 5A). Methylation interference studies indicate that SRF contacts nucleotides within the inner core of the SRE (Fig. 5A; Gilman et al. 1986; Treisman 1986). By analogy to the control elements of mating-type-specific genes in yeast, we considered the possibility that additional factors play a role in the regulation of c-fos transcription by interacting with the outer palindromic arms of the SRE. In the yeast system, the central core of an upstream activating sequence binds a ubiquitous factor, the general regulator of mating/pheromone receptor transcription factor (GRM/PRTF), whereas the outer arms bind cellspecific factors required for activation or repression (Bender and Sprague 1987; Keleher et al. 1988). The hypothesis that c-fos expression is regulated by an analogous mechanism was attractive because SRF contains homology to the gene that encodes GRM/PRTF (Norman et al. 1988), and GRM/PRTF can bind to the SRE (Hayes et al. 1988). If multiple factors with distinct binding requirements interact with the SRE to regulate transcription, then the appropriate mutation of the SRE might distinguish the binding of these factors and dissociate the activation and repression functions of the SRE.

Five mutant SRE elements containing substitutions or deletions in the inner core and outer arms of the SRE (Fig. 5A) were first tested for their ability to confer serum inducibility upon $\mathrm{pF} 222$. In this experiment, transcriptional activation was determined by RNase protection analysis of RNA from stably transfected cell lines. Southern analysis indicates that each cell line contains an approximately equal number of copies of the appropriate construct (data not shown). As shown in Figure $6 \mathrm{~A}, \mathrm{pF} 222$ shows a weak induction of properly initiated transcription upon serum stimulation. This induction is probably the result of the presence of weak serum responsive sequences contained within the proximal 222 nucleotides of upstream c-fos sequence (Treisman 1985; Greenberg et al. 1987; Sassone-Corsi et al. 1988). When mutant SREs containing a substitution (SREmut2) or deletion (SREmut3) of the inner core are fused to pF222, a low level of serum inducibility, comparable to that of pF222, is seen (Fig. 6A). This low level of serum induci-
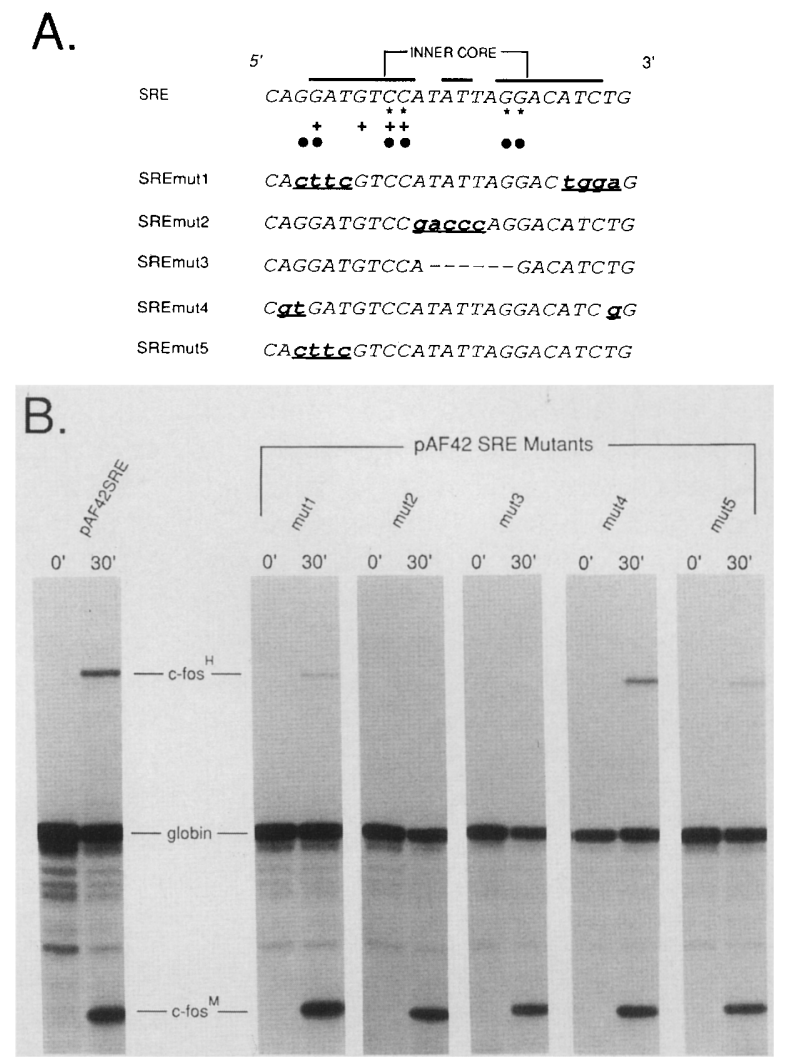

Figure 5. The effects of SRE mutations on the ability of the element to confer serum inducibility upon a truncated c-fos promoter. (A) Wild-type and mutant SREs. The top strand of DNA is shown. Oligonucleotides cloned into c-fos deletion constructs have EcoRI ends, as described in Methods. The 10-bp inner core and the region of dyad symmetry are marked above the wild-type SRE sequence. Listed below the sequence are the contacts made by SRF $\left({ }^{*}\right)$, p62/MAPF $1+1$, or a p62/SRF complex (O) with either strand of the SRE, as determined previously by the methylation interference assay (references are cited within the text). The five mutant SRE elements are listed, with mutant nucleotides indicated by underlined, lowercase letters. Deleted nucleotides are represented by dashes. $|B|$ The 3T3 cells were cotransfected with the human c-fos deletion plasmid pAF42 containing the indicated wild-type or mutant SRE oligonucleotide at position -42 of the promoter and an internal control plasmid, pSV $\alpha 1$. Quiescent cells were left unstimulated (0) or stimulated for 30 min with $20 \%$ fetal bovine serum; cytoplasmic RNA was isolated and analyzed by the RNase protection assay. Probe fragments specifically protected by transcripts from the transfected human c-fos (c-fos ${ }^{\mathrm{H}}$ ) and $\alpha$-globin (globin) genes, and the endogenous mouse c-fos gene $\left(\mathrm{c}-f_{0} s^{\mathrm{M}}\right)$ were separated by gel electrophoresis and visualized by autoradiography.

bility is more easily detected upon longer exposure of the autoradiograph (data not shown). In contrast, insertion of the wild-type SRE and SREmut4, in which only the extreme outer arms of the SRE are mutated, dramatically increases the serum responsiveness of pF222. SREmutl and SREmut5, which have substitutions on both or one arm of the SRE, also increase the serum inducibility of $\mathrm{pF} 222$, but to a lesser degree than the wildtype SRE.

To extend these results and to quantitate the relative 


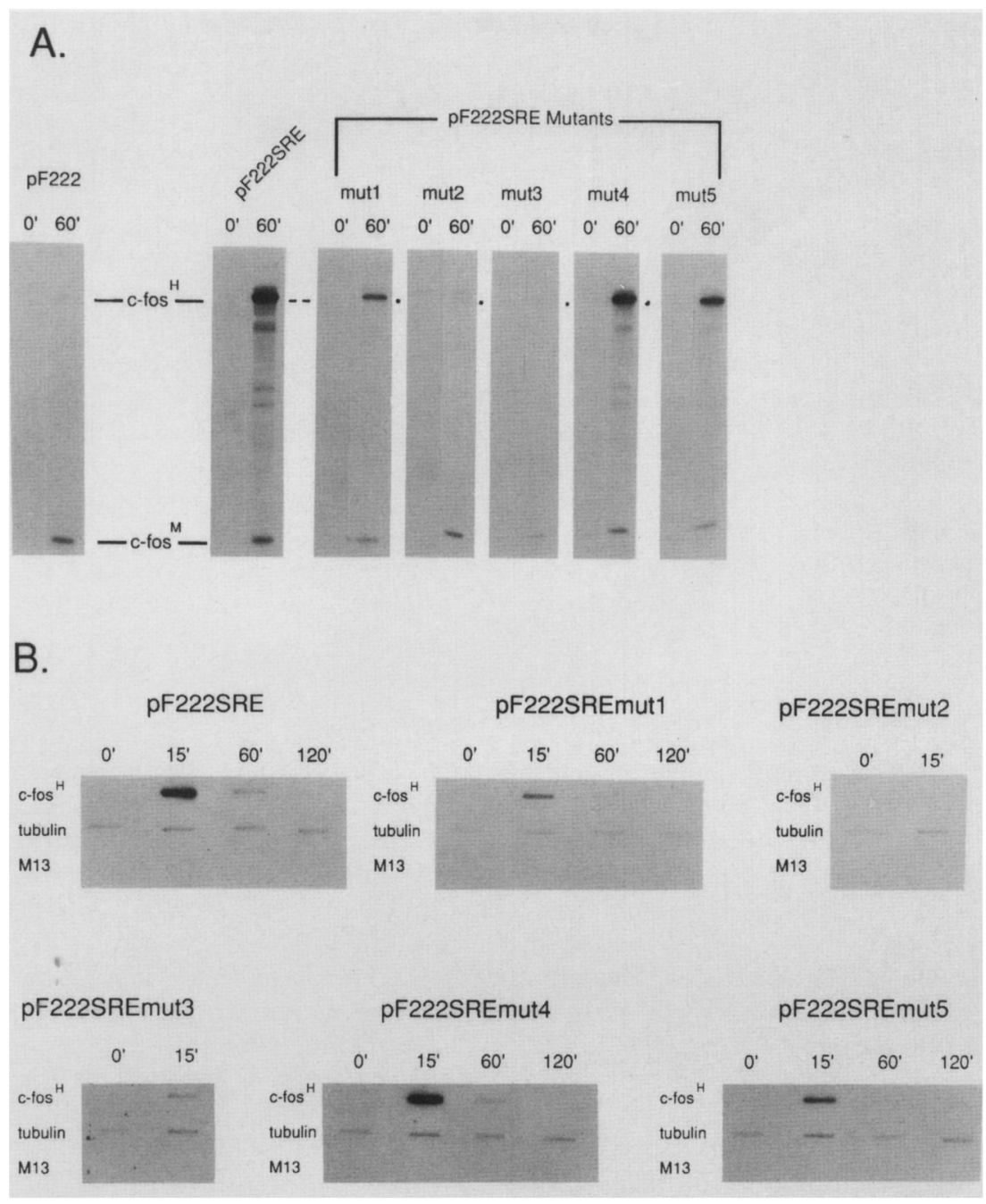

Figure 6. The inner core of the SRE is sufficient to direct the rapid induction and repression of c-fos transcription. 3T3 cells stably transfected with the indicated plasmids were analyzed by RNase protection $(A)$ and nuclear run-on $(B)$ assays, as described in Fig. 2. levels of inducibility conferred by the wild-type and mutant elements, each element was fused to a c-fos gene containing only 42 nucleotides of upstream sequence and the resulting constructs tested for serum responsiveness in a transient transfection assay. Transfection efficiency was monitored by measuring the expression of a cotransfected $\alpha$-globin gene expressed from the SV40 promoter. Relative levels of serum responsiveness were quantitated following normalization to the transfection efficiency. The results shown in Figure 5B are in complete agreement with those obtained using stably transfected cell lines (Fig. 6A). SREmut2 and SREmut3 are unresponsive to serum stimulation, SREmutl and SREmut5 are two- to threefold less inducible than the wild-type SRE, and SREmut4 is at least as inducible as the wild-type. These results suggest that the inner core of the SRE is essential for the ability of this element to confer serum inducibility but that the sequence of the outer arms can modulate the effect.

One possible explanation for the effects of these mutations on the degree of serum inducibility conferred by the SRE is that they alter the affinity of the element for SRF. Therefore, we determined the ability of the mutant
SREs to compete for the binding of in vitro-transcribed and translated SRF in a DNA mobility-shift assay. We found that the ability of each element to bind SRF in vitro (Fig. 7) correlates directly with its ability to mediate serum induction in vivo (Figs. 5B and 6A). Equivalent relative affinities were observed when each mutant SRE was labeled and tested for its ability to bind SRF directly (data not shown). This mutational analysis indicates that the integrity of the inner core must be maintained for SRF recognition and that the sequences of the outer arms appear only to modulate the affinity of the interaction. Similar conclusions have been obtained by testing the ability of mutant SRE elements to bind SRF found in HeLa cell nuclear extracts (Leung and Miyamoto 1989).

Although the outer arms of the SRE are not required for the rapid induction of c-fos transcription, the possibility remains that these sequences and any factor that interacts with them may be required for the proper down-regulation of transcription. We tested this possibility by examining the kinetics of transcription directed by mutant SRE elements fused to $\mathrm{pF} 222$. Figure $6 \mathrm{~B}$ shows that SREmut1, SREmut4, and SREmut5, which 


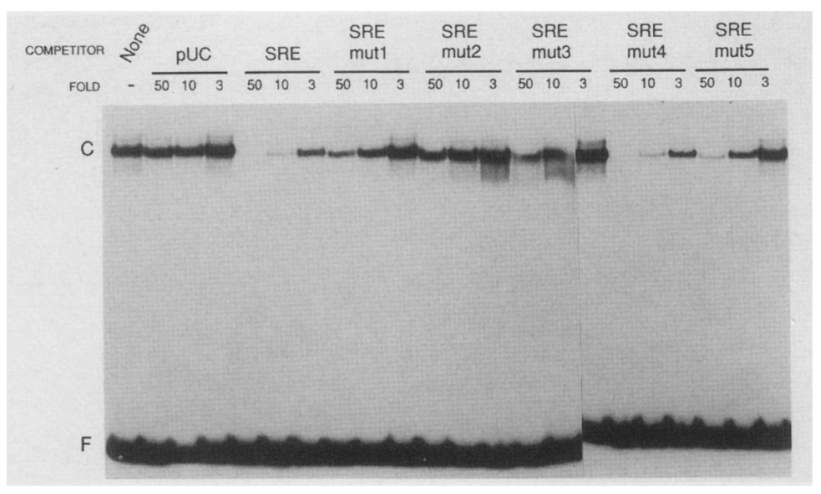

Figure 7. The effects of mutations in the c-fos SRE on SRF binding. Wild-type and mutant SRE elements (Fig. 5A) were cloned into pUC19 and tested for their ability to bind SRF by competition analysis in a DNA mobility-shift assay. In vitrotranscribed and translated SRF protein was incubated with a ${ }^{32}$ P-labeled DNA fragment spanning the SRE (nucleotides - 332 to -272 of the c-fos promoter) in the presence of a $50-, 10-$, or 3 -fold molar excess of the indicated competitor plasmid. Reactions were electrophoresed in a nondenaturing polyacrylamide gel, and the free $(\mathbf{F})$ and complexed $(\mathrm{C})$ DNA visualized by autoradiography.

contain mutations in the outer arms of the SRE, all direct wild-type kinetics of transcriptional induction and repression. This indicates that the regulation of the rapid and transient kinetics of c-fos transcription in response to serum is not dependent on the outer palindromic arms of the SRE and, hence, must not require the binding of factors to these sites. Therefore, despite the similarity between SRF and GRM/PRTF (Norman et al. 1988), the mechanism by which c-fos transcription is regulated in response to serum is distinct from that which controls the expression of mating-type-specific genes of yeast. The ability of SREmutl to direct the rapid induction and repression of c-fos transcription demonstrates that the 14-nucleotide inner core of the SRE is sufficient to mediate both transcriptional induction and repression.

As described above, SREmut2 and SREmut3 do not bind SRF (Fig. 7) and do not confer serum responsiveness upon truncated c-fos promoters (Figs. 5B and 6A). As shown in Figure 6B, the low, but detectable, level of serum induction of pF222SREmut2 and pF222SREmut3 seen in the RNase protection assay (Fig. 6A) is also observed in the same cell lines when analyzed by the nuclear run-on assay. The apparent increased responsiveness of SREmut3 relative to SREmut2 is not reproducibly observed (data not shown; Figs. $5 \mathrm{~B}$ and $6 \mathrm{~A}$ ). Interestingly, the low level of SRE-independent transcription observed in these mutants is also transient, returning to basal levels by $60 \mathrm{~min}$ after stimulation /data not shown). Therefore, although the SRE may be the major determinant of the transient transcriptional response of c-fos to serum, it may not be unique in its ability, as it appears that other elements within the c-fos promoter can mediate a transient, albeit weak, response. Consistent with this are the observations that regions of the c-fos promoter outside of the SRE that direct low levels of serum induction are also targets for the repressive effects of Fos (Sassone-Corsi et al. 1988; Wilson and Treisman 1988).

The involvement of accessory proteins in the regulation of c-fos transcription can also be assessed from these results. Figure 5A shows the contacts made between the SRE and a p62/SRF complex (Shaw et al. 1989b) or the SRE and p62/MAPF1 (Ryan et al. 1989; Walsh 1989), as determined previously by methylation interference experiments. Although SREmut1, SREmut4, and SREmut5 each contain mutations in nucleotides believed to be important for the formation of these complexes, we find that these mutant SREs still confer proper c-fos regulation. Therefore, if p62, p62/MAPF1, or other accessory factors are involved in the regulation of transcription, then they must function by interacting directly with SRF or by binding the SRE without a strict requirement for the nucleotide sequence of the outer arms.

\section{Fos-Jun complexes do not interact with the SRE or SRF}

Recent experiments have suggested that the Fos protein negatively regulates its own expression, possibly through an interaction with AP-1-like sites within the c-fos promoter (Sassone-Corsi et al. 1988; Wilson and Treisman 1988; Schonthal et al. 1989|. However, the results presented here demonstrate that these AP-1-like sites are not required for proper down-regulation. Nevertheless, Fos could play a direct role in the repression event by interacting with the inner core of the SRE. To address this possibility, we tested the ability of Fos, alone or in combination with members of the Jun family (Hirai et al. 1989; Ryder et al. 1989) and SRF, to interact with the SRE in a DNA mobility-shift assay. Fos, c-Jun, Jun-B, and SRF proteins were synthesized in an in vitro translation system programmed with RNA transcribed from cDNA clones encoding these proteins (Halazonetis et al. 1988).

Figure 8 shows that SRF binds a fragment of the c-fos promoter containing the SRE and the adjacent AP-1-like site (Fig. 8A, lane 1). Fos, c-Jun, and Jun-B, however, do not interact with this element, either alone or in combination (Fig. 8A, lanes 2-6). Under the same conditions, Fos-Jun complexes, but not Fos alone, do form a specific complex with a consensus AP-1-binding site (Fig. 8B), as described previously (Halazonetis et al. 1988; Kouzarides and Ziff 1988; Nakabeppu et al. 1988; Rauscher et al. 1988). This argues against a model in which Fos, either alone or in association with one of the Jun proteins, down-regulates transcription by binding directly to the SRE. Because the AP-1-like element adjacent to the SRE is also present within the fragment used for these experiments, these results further indicate that Fos does not down-regulate transcription through an interaction with this site.

We asked whether Fos might interact with the SRE in the presence of SRF. We find that Fos and Jun proteins do not interact with the SRE/SRF complex either alone or in combination, as addition of these proteins to the 


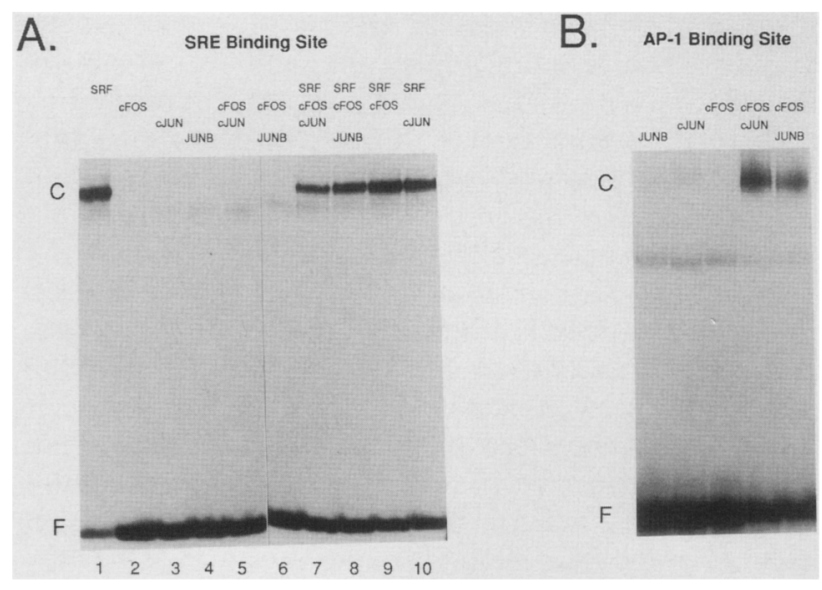

Figure 8. Fos and Fos-Jun complexes do not interact with the SRE or SRF. The DNA mobility-shift analysis used in vitrotranscribed and translated c-Fos, c-Jun, Jun-B, and SRF proteins. Proteins were incubated in the indicated combinations with a ${ }^{32}$ P-labeled DNA fragment spanning the SRE $(A)$, as described in Fig. 7, and a ${ }^{32}$ P-labeled oligonucleotide containing the AP-1binding site $(B)$. The binding reactions were analyzed by electrophoresis on a nondenaturing polyacrylamide gel, and free $(F)$ and complexed $\{C \mid$ DNA visualized by autoradiography.

binding reactions has no effect on the SRE/SRF shift pattern (Fig. 8A, lanes 1 and 7-10). Similarly, SRF does not alter the interaction of Fos-Jun complexes with the AP-1 site (data not shown). The data suggest that Fos does not shut off its own transcription by binding directly to the SRE or SRF; however, these experiments do not exclude the possibility that accessory factors are required for a Fos-SRE interaction.

\section{Discussion}

To begin to elucidate the mechanism by which c-fos transcription is rapidly repressed following serum stimulation, we systematically mutated the c-fos gene to identify the critical sequence elements that mediate the shutoff event. Using a nuclear run-on assay to follow directly the kinetics of serum-induced transcription from transfected genes, we demonstrate that the SRE can confer both the rapid induction and subsequent repression of transcription on a minimal c-fos promoter or a heterologous gene. Furthermore, the SRE mediates this transient response in the absence of a recognizable TATA element. These results strongly suggest that the SRE is the site of regulation for both the induction and shutoff of c-fos transcription. Mutagenesis of the SRE demonstrates that an inner core sequence no larger than 14-bp is sufficient to mediate both events, indicating that the factors directing the activation and repression of c-fos transcription need recognize only this central core. Localization of the site of regulation to within this 14-bp sequence should facilitate further analysis of the mechanism by which c-fos transcription is rapidly repressed following growth factor stimulation.

The inner core of the SRE consists largely of a "CArG box $^{\prime \prime}$, a 10-bp CC(A/T) 6 GG motif first noted for its ability to confer muscle-specific expression on $\alpha$-actin genes (Bergsma et al. 1986; Minty and Kedes 1986; Muscat and Kedes 1987; Walsh and Schimmel 1988). Recently, CArG box elements from actin genes have also been shown to confer serum inducibility on a heterologous gene (Subramaniam et al. 1989; Taylor et al. 1989), suggesting that the 10-bp CArG box within the c-fos SRE alone is able to mediate transcriptional induction in response to serum. It remains to be shown that the CArG box is also sufficient to mediate the repression of c-fos transcription following serum stimulation. However, several recent findings support this possibility. First, the promoter regions of two immediate early genes, which are coinduced and repressed with c-fos, Krox-20, and zif/268, both contain CArG box elements lacking palindromic flanking sequences (Chavrier et al. 1989; Christy et al. 1988). Second, a CArG box element can mediate the superinduction of the transcriptional response to serum that is brought about by treatment with cycloheximide (Subramaniam et al. 1989). Third, the two factors that have been shown to interact directly with the c-fos SRE, SRF, and p62/MAPF1 appear to be the same two factors that interact with the CArG boxes of $\alpha$-actin genes (Phan-Dinh-Tuy et al. 1988; Boxer et al. 1989; Ryan et al. 1989; Taylor et al. 1989; Walsh 1989|.

We and others (Treisman 1987; Greenberg et al. 1987; Gilman 1988/ have found that mutations in the SRE that disrupt the in vitro binding of SRF also abolish the ability of the element to confer serum inducibility on an unresponsive human c-fos or CAT reporter gene. In addition, when examined in 3T3 cells, these SRE mutants caused no change in the level of transcription from the transfected gene in unstimulated cells. In contrast, two recent reports (Leung and Miyamoto 1989; Shaw et al. 1989a) suggest that mutations in the SRE increase the unstimulated levels of transcription of heterologous reporter genes in HeLa cells. This difference between our results and those of others may be explained, in part, by the reporter constructs and cell lines used for analysis. First, the use of the stable $\beta$-globin or SV40 early mRNAs as reporters (Leung and Miyamoto 1989; Shaw et al. 1989a) facilitates the detection of low levels of transcription that may be undetectable when, as in our experiments, the highly unstable human c-fos message (Kruijer et al. 1984) is used as a reporter. A second possible explanation for the altered response of SRE mutants in these experiments is that HeLa and 3T3 cells may contain different levels of activator and repressor factors. For example, the results obtained in HeLa cells could be explained if mutation of the SRE simultaneously abolished SRF binding while allowing the interaction of a HeLa cell-specific activating factor with a nearby site.

The finding that the inner core of the SRE is sufficient for appropriate serum regulation of c-fos transcription allows for several possible functions for the palindromic outer arms. These arms have been conserved in the SREs of human, mouse, and chicken c-fos genes (Treisman 
1985; Fujiwara et al. 1987) and in the SRE of another serum-inducible gene, Xenopus laevis $\gamma$-actin (Mohun et al. 1987), but not in the Xenopus c-fos SRE (Taylor et al. 1989|. Our results demonstrate that one function of the outer palindromic arms of the human c-fos SRE is to strengthen the binding of SRF and to enhance the transcriptional response to serum. It is of interest that other serum-inducible genes that contain CArG box elements, but lack the palindromic outer arms, have multiple copies of these elements [Krox-20 (Chavrier et al. 1989); zif/268 (Christy et al. 1988); human $\beta$-actin (Frederickson et al. 1989). This may reflect an alternate mechanism that has evolved to modulate the strength of the transcriptional response to serum. In the SRE from mammalian c-fos genes, where the outer arms are particularly well-conserved, these sequences may also function as binding sites for additional regulatory factors important for the transcriptional control of c-fos in response to other environmental cues or in different cell types.

On the basis of the experiments described here, we envisage several models to explain the mechanism by which the inner core of the SRE mediates both the induction and repression of c-fos transcription. In the first model, the regulation of both events requires the direct binding of only SRF to the SRE. In this case, the activation and repression of c-fos would be controlled by the post-translational modification of SRF or an SRF-associated factor, such as the p62 factor described by Shaw et al. $(1989 \mathrm{~b})$. In the second model, c-fos regulation would be controlled by the direct binding of multiple factors to the inner core of the SRE. One simple version of this model postulates that separate activator and repressor proteins bind in a mutually exclusive manner to distinct sites. Recent in vivo footprinting data, however, argue against this possibility, as the binding of factors to the SRE appears unaltered before, during, and after growth factor stimulation of c-fos (Herrera et al. 1989). It remains possible that a separate activator and repressor protein bind to an identical site within the SRE. The recent generation of anti-SRF antibodies (R. Misra, V.M. Rivera, J.M. Wang and M.E. Greenberg, unpubl.) will facilitate further investigation of the potential modifications of SRF and its association with additional factors, as well as the identification of SRF-related factors.

A third model to explain the mechanism of transcriptional induction and repression of $\mathrm{c}$-fos postulates that SRF and additional factors that interact with the SRE are required to enhance the transcriptional response to serum but are not, themselves, the regulated factors. Instead, the regulation of these events could involve a modification of a component of the basic transcription machinery that promotes initiation or relieves a block in transcriptional elongation. Consistent with this possibility is the finding that additional enhancers not found in the c-fos gene can substitute for the SRE to mediate both the induction and repression of c-fos transcription (V.M. Rivera, unpubl.).

What is the role of the c-fos gene product in the shutoff event? We have demonstrated that AP-1-like sites within the c-fos gene are not essential for the shutoff of transcription, thus ruling out the possibility that Fos-Jun complexes repress transcription by binding to these sites. Furthermore, it has been shown recently that a mutant Fos protein that cannot dimerize with Jun and has therefore has lost its ability to bind to an AP-1 element still retains its ability to repress expression of its own gene (Schonthal et al. 1989). Therefore, the autoregulatory role of Fos may involve a novel function of the protein that is not related to its ability to bind an AP-1 sequence. We cannot exclude the possibility that Fos is directly involved in the shutoff of transcription via an interaction with the SRE or the factors that bind to it. However, we found that under conditions in which Fos-Jun complexes bound efficiently to an AP-1 element, Fos and Fos-Jun complexes failed to bind directly to the SRE or interact with SRF. Therefore, if Fos interacts directly with SRF or the SRE, it is likely to require additional modifications or factors that are not required for an interaction with Jun or an AP-1 site. Alternatively, Fos may play an indirect role in the shutoff event by affecting the activity or expression of another nuclear factor which then controls c-fos transcription.

While this paper was under review for publication, Konig et al. (1989) reported that a minimal construct containing the SRE and a TATA box (1) is sufficient to confer both the rapid induction and repression of transcription upon a heterologous gene and (2) is a target for the repressive effects of Fos overexpression.

\section{Methods \\ Plasmid constructions}

Plasmids pF4, pF711, and pF222 were gifts from Richard Treisman (Treisman 1985). pF4 contains the entire genomic human c-fos gene, including $750 \mathrm{bp}$ of the promoter inserted into the BamHI site of pUC12. pF711, pF222, and pF42 (Sheng et al. 1988) are $5^{\prime}$-deletion derivatives of $\mathrm{pF} 4$, which contain 711,222 , and 42 bp of sequence upstream of the mRNA start site, respectively. The following plasmids have been described previously (Greenberg et al. 1987) but have been renamed as follows: pF222(332-272), previously pF222SRE; pF222(332-272) $\Delta 1$, previously pF222SREmut23, pF222SRE, previously pF222DSE. pF42SRE was constructed by inserting a 29mer SRE oligonucleotide (Greenberg et al. 1987) at position -42 of pF42. pAF42 is identical to pF42, except that the AatII site in the pUC vector, which forms part of a CRE-like element, was destroyed (M. Sheng et al., in prep.).

$\mathrm{p} \beta$-Globin and $\mathrm{p} \beta$-globin/SRE were gifts from Zahava Siegfried (Siegfried and Ziff 1989). M13mp9 3 -globin, a gift from Gray Shaw (Shaw and Kamen 1986), pSV2neo (Southern and Berg 1982), pBBB, and $\mathrm{pSV} \alpha 1$ (Shyu et al. 1989) have all been described previously.

Plasmids used to detect specific RNA transcripts in the nuclear run-on assay were constructed as follows. M13Goril, a gift from Joel Belasco, is a wild-type $\mathrm{M} 13$ derivative containing a 2216-bp HaeI fragment of bacteriophage G4 cloned into the HaeI site within the intergenic region of M13 (Kaguni and Ray 1979). This HaeI region was then used as a polylinker for the construction of the following:

M13HPPA The 471-bp PstI fragment from the second intron of the human c-fos gene was cloned into PstI-cut M13mp18 in 
the sense orientation to create M13mp18HPPS. The 515-bp HindIII (filled in)-SacI fragment was inserted into SacI-PvaII cut M13Goril.

M13CATA The 780-bp BamHI fragment of pCM4 (Pharmacia, Piscataway, New Jerseyl, which contains the CAT gene, was inserted into BamHI-cut pUC19 to create CAT/pUC19 /a gift from Lishan Sul. The 820 bp SacI-SphI fragment was cloned into SacI-SphI-cut M13Goril.

M13MATA The 720-bp EcoRI fragment of mouse $\alpha$-tubulin was inserted into EcoRI-cut M13Goril in the antisense orientation.

pFC700, pFCpm1, and pFCpm2 were gifts from Celeste Simon. pFC700 (Fisch et al. 1987) contains the human c-fos promoter from -710 to +42 fused to the CAT gene. pFCpm 1 (Fisch et al. 1989b) and pFCpm2 (Simon et al. 1990) are derivatives of pFC700 that contain point mutations in the c-fos TATA box, as indicated in Figure 4A.

SRE mutant oligonucleotides, shown in Figure 5A, were first synthesized as single strands containing the nucleotides GGCGAATT and AATTCAG, 5' and $3^{\prime}$, respectively, to the sequence shown in the text. Complementary strands were generated by the self-priming method of Hill et al. (1987), and the resulting double-stranded oligonucleotides were cleaved with EcoRI to generate an oligonucleotide containing the indicated SRE mutant sequence with EcoRI ends. These oligonucleotides were then inserted into the EcoRI sites of pF222, pAF42, and pUC19 and sequenced.

The following plasmids used for in vitro transcription reactions have been described previously: T7 $\triangle A T G-S R F$ (a gift from Richard Treisman; Norman et al. 1988); pGEMfos3 and pGEMjunl (a gift from Thanos Halazonetis, Halazonetis et al. 1988). pGEMjunB was constructed by inserting the $1.5-\mathrm{kb}$ EcoRI fragment of $\mathrm{p} 465.20$ (a gift from Dan Nathans; Ryder et al. 1989), which contains the Jun-B gene, into the EcoRI site of pGEM4 such that transcription by SP6 polymerase produces the sense RNA transcript.

DNA, labeled with ${ }^{32} \mathrm{P}$, for binding reactions was derived from the following plasmids: SRE/pUC19 contains a 65-bp oligonucleotide spanning the c-fos SRE (Greenberg et al. 1987), cloned into the EcoRI site of pUC19. AP1/pUC19 contains the following oligonucleotide cloned into the EcoRI site of pUC19: 5'-AATTCAAACATGACTCAGAGGAAAACATACG-3' annealed to is complementary strand.

\section{Cell culture and transfection}

Mouse NIH-3T3 cells were passaged in Dulbecco's modified Eagle medium (DMEM) with $10 \%$ calf serum. Cells were split to a density of $2 \times 10^{6}$ per $100-\mathrm{mm}$ dish, $18 \mathrm{hr}$ prior to transfection, as described previously (Greenberg et al. 1987).

In transient assays, cells were transfected with a DNA mixture containing $10 \mu \mathrm{g}$ of the test plasmid, $2 \mu \mathrm{g}$ of the internal control $\alpha$-globin plasmid $(\mathrm{pSV} \alpha 1)$, and $8 \mu \mathrm{g}$ of carrier plasmid (pUC19). Twelve to $16 \mathrm{hr}$ after transfection, cells were washed with $1 \times$ PBS and serum-starved in DMEM/0.5\% calf serum for 24-30 hr.

Stably transfected cells were isolated as follows. Twelve to 16 $\mathrm{hr}$ after transfection with a DNA mixture containing $5 \mu \mathrm{g}$ of test plasmid, $1 \mu \mathrm{g}$ of the selectable marker (pSV2neo), and $14 \mu \mathrm{g}$ of carrier plasmid (pUC19), cells were washed with $1 \times$ PBS and grown in DMEM $/ 10 \%$ calf serum. Each dish was split $1: 20$ into selective medium (DMEM/10\% calf serum $/ 300 \mu \mathrm{g} / \mathrm{ml}$ G418) $48 \mathrm{hr}$ later. Cells were re-fed selective medium every 4 days. Fourteen to 20 days later, 50-100 colonies were pooled and passaged. For analysis, cells were passaged at $5 \times 10^{6}$ per $150-\mathrm{mm}$ dish in DMEM/10\% calf serum. Fourteen to $20 \mathrm{hr}$ later, cells were starved in DMEM $/ 0.5 \%$ calf serum for $24-30$ hr.

\section{RNase protection and nuclear run-on assays}

Starved cells were stimulated with DMEM/20\% fetal bovine serum for the indicated amount of time. Total cytoplasmic RNA was isolated and analyzed by the RNase protection assay (Treisman 1985; Sheng et al. 1988). Nuclei were harvested and analyzed by the nuclear run-on assay (Ausubel et al. 1987) with the following modifications. Two micrograms of denatured double-stranded or single-stranded DNA was spotted onto nylon membrane filters, using a slot-blot apparatus and subsequently UV cross-linked. Hybridization of ${ }^{32} \mathrm{P}$-labeled RNA $\left(0.5 \times 10^{6}\right.$ to $\left.6 \times 10^{6} \mathrm{cpm} / \mathrm{ml}\right)$ to nylon filters spotted with DNA was performed at $65^{\circ} \mathrm{C}$ for $36-44 \mathrm{hr}$ in the presence of $1 \times$ Denhardt's solution and $250 \mu \mathrm{g} / \mathrm{ml}$ yeast RNA. Following hybridization, filters were washed twice in $0.1 \% \mathrm{SDS} / 2 \times \mathrm{SSC}$ for $15 \mathrm{~min}$ at room temperature and once in $0.1 \% \mathrm{SDS} / 0.1 \times \mathrm{SSC}$ for $30 \mathrm{~min}$ at $60^{\circ} \mathrm{C}$, and exposed to X-ray film.

Two modifications of the nuclear run-on assay (Ausubel et al. 1987) enabled us to follow the kinetics of transcription from transfected genes. The first modification is the use of stable cell lines, rather than transiently transfected cells for the isolation of nuclei. The results of run-on transcription assays using nuclei from transiently transfected cells are often not reproducible, possibly due to the release of plasmid DNA from the nuclei during their isolation. The use of pooled, stably transfected cell lines circumvents this problem because the transfected DNA becomes integrated into the cellular genome. Second, because the transfected test plasmid and selectable marker plasmid (pSV2neo) were found to produce ${ }^{32}$-labeled transcripts that extend into the $\mathrm{pBR}$ or pUC vector sequences (V.M. Rivera, unpubl.), the DNA probes cross-linked to filters had to be devoid of sequences homologous to these vectors. Because the wild-type M13 plasmid meets this criterion, a wild-type M13-derivative plasmid (M13Goril) was used as the cloning vehicle for the DNA probes.

\section{In vitro transcription and translation}

Prior to in vitro transcription, the plasmid DNAs encoding the mRNAs were linearized with the following restriction enzymes: pGEMfos3, HindIII; pGEMiunl, PvuII; pGEMjun-B, HindIII; and pT7 $\triangle A T G-S R F, B a m H I$. Then mRNAs were transcribed in vitro from the linearized plasmids using SP6 RNA polymerase (for c-fos, c-jun, and jun-B) or T7 RNA polymerase (for SRF) as described previously (Halazonetis et al. 1988). The in vitro-transcribed RNAs were translated using a micrococcal nuclease-treated rabbit reticulocyte lysate, as described (Halazonetis et al. 1988).

\section{DNA binding assay}

In vitro-translated proteins were assayed for DNA binding to the c-fos SRE or the AP-1 sequence as described previously (Halazonetis et al. 1988), with the following modifications. In vitro-translated proteins were used immediately upon synthesis or after storage at $-80^{\circ} \mathrm{C}$. When the binding of several proteins was analyzed in the same reaction, $1.5 \mu$ l of each of the proteins was mixed and incubated at $37^{\circ} \mathrm{C}$ for $30 \mathrm{~min}$. Six microliters of DNA-binding buffer $[50 \mathrm{~mm} \mathrm{NaCl}, 10 \mathrm{~mm}$ Tris- $\mathrm{HCl}$ (pH 7.4), $1 \mathrm{~mm} \mathrm{MgCl}_{2}, 1 \mathrm{~mm}$ EDTA, $1 \mathrm{~mm}$ DTT, 5\% 
glycerol, $100 \mu \mathrm{g} / \mathrm{ml}$ poly[d(I-C)], $1 \mathrm{~mm}$ phenylmethylsulfonyl fluoride, $100 \mathrm{kallikrein}$ inactivator $\mathrm{U} / \mathrm{ml}$ aprotinin) was added. Following a 10-min incubation at room temperature, $1 \mu \mathrm{l}$ of ${ }^{32} \mathrm{P}$-labeled DNA was added, and the samples were left at room temperature for an additional $15 \mathrm{~min}$. Then, $2.5 \mu \mathrm{l}$ of loading buffer $(1.5 \times$ DNA binding buffer with $0.1 \%$ bromphenol blue and $0.1 \%$ xylene cyanol) was added, and the reactions were analyzed on a $5 \%$ polyacrylamide gel in TAE buffer as, described previously, except that the gels were prerun for only $2 \mathrm{hr}$.

The ${ }^{32} \mathrm{P}$-labeled DNA used in the binding assays was prepared by releasing the SRE or AP-1 fragments from SRE/pUC19 or AP1/pUC19, respectively, by digestion with EcoRI. The fragments were labeled and gel-purified, as described by Halazonetis et al. (1988).

\section{Acknowledgments}

We gratefully acknowledge the following people for their gifts of plasmids: Joel Belasco, Thanos Halazonetis, Dan Nathans, Gray Shaw, Ann-Bin Shyu, Zahava Siegfried, Celeste Simon, Lishan Su, and Richard Treisman. This work was supported by grant RO1-CA-43855 from the National Institutes of Health. M.E.G. is the recipient of an American Cancer Society Junior Faculty Research Award (JFRA-179) and is a Searle scholar supported by the Chicago Community Trust. V.M.R. is supported by a National Science Foundation predoctoral fellowship. M.S. is supported by a Lucille P. Markey predoctoral fellowship.

\section{References}

Almendral, J.M., D. Sommer, H. MacDonald-Bravo, J. Burckhardt, J. Perera, and R. Bravo. 1988. Complexity of the early genetic response to growth factors in mouse fibroblasts. Mol. Cell. Biol. 8: 2140-2148.

Angel, P., M. Imagawa, R. Chiu, B. Stein, R.J. Imbra, H.J. Rahmsdorf, C. Jonat, P. Herrlich, and M. Karin. 1987. Phorbol ester-inducible genes contain a common cis element recognized by a TPA-modulated trans-acting factor. Cell 49: 729-739.

Ausubel, F.M., R. Brent, R.E. Kingston, D.D. Moore, J.G. Seidman, J.A. Smith, and K. Struhl. 1987. Current protocols in molecular biology. Greene Publishing and John Wiley, New York.

Bender, A. and G.F. Sprague. 1987. MAT $\alpha 1$ protein, a yeast transcription activator, binds synergistically with a second protein to a set of cell-type-specific genes. Cell 50: 681-691.

Bergsma, D.J., J.M. Grichnik, L.M.A. Gossett, and R.J. Schwartz. 1986. Delimitation and characterization of cisacting DNA sequences required for the regulated expression and transcriptional control of the chicken skeletal $\alpha$-actin gene. Mol. Cell. Biol. 6: 2462-2475.

Boxer, L.M., R. Prywes, R.G. Roeder, and L. Kedes. 1989. The sarcomeric actin CArG-binding factor is indistinguishable from the c-fos serum response factor. Mol. Cell. Biol. 9: $515-522$.

Chavrier, P., U. Janssen-Timmen, M.-G. Mattei, M. Zerial, R. Bravo, and P. Charnay. 1989. Structure, chromosome location, and expression of the mouse zinc-finger gene Krox-20: Multiple gene products and coregulation with the proto-oncogene c-fos. Mol. Cell. Biol. 9: 787-797.

Chen, W. and K. Struhl. 1988. Saturation mutagenesis of a yeast his3 "TATA element": Genetic evidence for a specific TATA-binding protein. Proc. Natl. Acad. Sci. 85: 26912695.
Chiu, R., W.J. Boyle, J. Meek, T. Smeal, T. Hunter, and M. Karin. 1988. The c-fos protein interacts with c-jun/AP-1 to stimulate transcription of AP-1 responsive genes. Cell 54: 541-552.

Christy, B.A., L.F. Lau, and D. Nathans. 1988. A gene activated in mouse 3T3 cells by serum growth factors encodes a protein with "zinc finger" sequences. Proc. Natl. Acad. Sci. 85: 7857-7861.

Cochran, B.H., A.C. Reffel, and C.D. Stiles. 1983. Molecular cloning of gene sequences regulated by platelet-derived growth factor. Cell 33: 939-947.

Fisch, T.M., R. Prywes, and R.G. Roeder. 1987. c-fos sequences necessary for basal expression and induction by epidermal growth factor, 12-O-tetradecanoyl phorbol-13-acetate, and the calcium ionophore. Mol. Cell. Biol. 7: 3490-3502.

- 1989a. An APl-binding site in the c-fos gene can mediate induction by epidermal growth factor and 12-O-tetradecanoyl phorbol-13-acetate. Mol. Cell. Biol. 9: 1327-1331.

Fisch, T.M., R. Prywes, M.C. Simon, and R.G. Roeder. 1989b. Multiple sequence elements in the c-fos promoter mediate induction by cAMP. Genes Dev. 3: 198-211.

Frederickson, R.M., M.R. Micheau, A. Iwamoto, and N.G. Miyamoto. 1989. 5' Flanking and first intron sequences of the human $\beta$-actin gene required for efficient promoter activity. Nucleic Acids Res. 17: 253-270.

Fujiwara, K.T., K. Ashida, H. Nishina, H. Iba, N. Miyajima, M. Nishizawa, and S. Kawai. 1987. The chicken c-fos gene: Cloning and nucleotide sequence analysis. I. Virol. 61: 4012-4018.

Gilman, M.Z., R.N. Wilson, and R.A. Weinberg. 1986. Multiple protein binding sites in the $5^{\prime}$-flanking region regulate c-fos expression. Mol. Cell. Biol. 6: 4305-4315.

Gilman, M.Z. 1988. The c-fos serum response element responds to protein kinase C-dependent and -independent signals, but not to cyclic AMP. Genes Dev. 2: 394-402.

Greenberg, M.E. and E.B. Ziff. 1984. Stimulation of 3 T3 cells induces transcription of the c-fos proto-oncogene. Nature 311: 433-438.

Greenberg, M.E., A.L. Hermanowski, and E.B. Ziff. 1986. Effect of protein synthesis inhibitors on growth factor activation of c-fos, c-myc, and actin gene transcription. Mol. Cell. Biol. 6: 1050-1057.

Greenberg, M.E., Z. Siegfried, and E.B. Ziff. 1987. Mutation of the c-fos dyad symmetry element inhibits serum inducibility in vivo and nuclear regulatory factor binding in vitro. Mol. Cell. Biol. 7: 1217-1225.

Halazonetis, T.D., K. Georgopoulos, M.E. Greenberg, and P. Leder. 1988. c-jun dimerizes with itself and with c-fos, forming complexes of different DNA binding affinities. Cell 55: $917-924$.

Hayes, T.E., A.M. Kitchen, and B.H. Cochran. 1987. Inducible binding of a factor to the c-fos regulatory region. Proc. Natl. Acad. Sci. 84: 1272-1276.

Hayes, T.E., P. Sengupta, and B.H. Cochran. 1988. The human c-fos serum response factor and the yeast factors GRM/ PRTF have related DNA-binding specificities. Genes Dev. 2: 1713-1722.

Herrera, R.E., P.E. Shaw, and A. Nordheim. 1989. Occupation of the c-fos serum response element in vivo by a multi-protein complex is unaltered by growth factor induction. Nature 340: $68-70$.

Hill, D.E., A.R. Oliphant, and K. Struhl. 1987. Mutagenesis with degenerate oligonucleotides: An efficient method for saturating a defined DNA region with base pair substitutions. Methods Enzymol. 155: 558-582.

Hirai, S.-I, R.-P. Ryseck, F. Mechta, R. Bravo, and M. Yaniv. 
1989. Characterization of junD: A new member of the jun proto-oncogene family. $E M B O$ I. 8: 1433-1439.

Kaguni, J. and D.S. Ray. 1979. Cloning of a functional replication origin of phage G4 into the genome of phage M13. I. Mol. Biol. 135: 863-878.

Keleher, C.A., C. Goutte, and A.D. Johnson. 1988. The yeast cell-type-specific repressor $\alpha 2$ act cooperatively with a noncell-type-specific protein. Cell 53: 927-936.

Konig, H., H. Ponta, U. Rahmsdorf, M. Buscher, A. Schonthal, H.J. Rahmsdorf, and P. Herrlich. 1989. Autoregulation of fos: The dyad symmetry element as the major target of repression. EMBO I. 8: 25592D2566.

Kouzarides, T. and E. Ziff. 1988. The role of the leucine zipper in the fos-jun interaction. Nature 336: 646-651.

Kruijer, W., J.A. Cooper, T. Hunter, and I.M. Verma. 1984. Platelet-derived growth factor induces rapid but transient expression of the c-fos gene and protein. Nature 312: 711716.

Lau, L.F. and D. Nathans. 1987. Expression of a set of growthrelated immediate early genes in BALB/c 3T3 cells: coordinate regulation with c-fos or c-myc. Proc. Natl. Acad. Sci. 84: $1182-1186$

Lee, W., P. Mitchell, and R. Tijan. 1987. Purified transcription factor AP-1 interacts with TPA-inducible enhancer elements. Cell 49: 741-752.

Leung, S. and N.G. Miyamoto. 1989. Point mutational analysis of the human c-fos serum response factor binding site. $\mathrm{Nu}$ cleic Acids Res. 17: 1177-1195.

Lim, R.W., B.C. Varnum, and H.R. Herschman. 1987. Cloning of tetradecanoyl phorbol ester-induced primary response sequences and their expression in density-arrested Swiss 3T3 cells and a TPA non-proliferative variant. Oncogene 1: 263270.

Lucibello, F.C., M. Neuberg, J.B. Hunter, T. Jenuwein, M. Schuermann, R. Wallich, B. Stein, A. Schonthal, P. Herrlich, and R. Muller. 1988. Transactivation of gene expression by c-fos protein: Involvement of a binding site for the transcription factor AP-1. Oncogene 3: 43-51.

Minty, A. and L. Kedes. 1986. Upstream regions of the human cardiac gene that modulate its transcription in muscle cells: Presence of an evolutionarily conserved repeated motif. Mol. Cell. Biol. 6: 2125-2136.

Mohun, T., N. Garret, and R. Treisman. 1987. Xenopus cytoskeletal actin and human c-fos gene promoters share a conserved protein-binding site. EMBO I. 6: 667-673.

Muscat, G.E.O. and L. Kedes. 1987. Multiple 5'-flanking regions of the human $\alpha$-skeletal actin gene synergistically modulate muscle-specific expression. Mol. Cell. Biol. 7: 4089-4099.

Nakabeppu, Y., K. Ryder, and D. Nathans. 1988. DNA binding activities of three murine jun proteins: Stimulation by fos. Cell 55: 907-915.

Norman, C., M. Runswick, R. Pollock, and R. Treisman. 1988. Isolation and properties of cDNA clones encoding SRF, a transcription factor that binds to the c-fos serum response element. Cell 55: 989-1003.

Phan-Dinh-Tuy, F., D. Tuil, F., Schweighoffer, C. Pinset, A. Kahn, and A. Minty. 1988. The "CC.Ar.GG" box: A protein site common to transcription-regulatory regions of the cardiac actin, c-fos and interleukin-2 receptor genes. Eur. $J$. Biochem. 173: 507-515.

Piette, J. and M. Yaniv. 1987. Two different factors bind to the $\alpha$-domain of the polyoma virus enhancer, one of which also interacts with the SV40 and c-fos enhancers. EMBO $J$. 6: $1331-1337$

Prywes, R. and R.G. Roeder. 1987. Purification of the c-fos en- hancer binding protein. Mol. Cell. Biol. 7: 3482-3489.

Rauscher, F.J., P.J. Voulalas, B.R. Franza, and T. Curran. 1988. Fos and Jun bind cooperatively to the AP-1 site: Reconstruction in vitro. Genes Dev. 2: 1687-1699.

Ryan, W.A., Jr., B.R. Franza, Jr., and M.Z. Gilman. 1989. Two distinct cellular phosphoproteins bind to the c-fos serum response element. $E M B O$ I. 8: 1785-1792.

Ryder, K., A. Lanahan, E. Perez-Albuerne, and D. Nathans. 1989. Jun-D: a third member of the jun gene family. Proc. Natl. Acad. Sci. 86: 1500-1503.

Sassone-Corsi, P., J.C. Sisson, and I. Verma. 1988. Transcriptional autoregulation of the proto-oncogene fos. Nature 334: 314-319.

Schonthal, A., P. Herrlich, H.J. Rahmsdorf, and H. Ponta. 1988. Requirement for fos gene expression in the transcription activation of collagenase by other oncogenes and phorbol esters. Cell 54: 325-334.

Schonthal, A., M. Buscher, P. Angel, H.J. Rahmsdorf, H. Ponta, K. Hattori, R. Chiu, M. Karin, and P. Herrlich. 1989. The Fos and Jun/AP-1 proteins are involved in the downregulation of Fos transcription. Oncogene 4: 629-636.

Shaw, G. and R. Kamen. 1986. A conserved AU sequence from the $3^{\prime}$ untranslated region of GM-CSF mRNA mediates selective mRNA degradation. Cell 46: 659-667.

Shaw, P.E., S. Frasch, and A. Nordheim. 1989a. Repression of c-fos transcription is mediated through p $67^{\mathrm{SRF}}$ bound to the SRE. EMBO I. 8: 2567-2574.

Shaw, P.E., H. Schroter, and A. Nordheim. 1989b. The ability of a ternary complex to form over the serum response element correlates with serum inducibility of the human c-fos promoter. Cell 56: 563-572.

Sheng, M., S.T. Dougan, G. McFadden, and M.E. Greenberg. 1988. Calcium and growth factor pathways of c-fos transcriptional activation require distinct upstream regulatory sequences. Mol. Cell. Biol. 8: 2787-2796.

Shyu, A.-B., M.E. Greenberg, and J.G. Belasco. 1989. The c-fos transcript is targeted for rapid decay by two distinct mRNA degradation pathways. Genes Dev. 3: 60-72.

Siegfried, Z. and E.B. Ziff. 1989. Transcription activation by serum, PDGF, and TPA through the c-fos DSE: cell type specific requirements for induction. Oncogene 4: 3-11.

Simon, M.C., T.M. Fisch, B.J. Benecke, J.R. Nevins, and N. Heintz. 1988. Definition of multiple, functionally distinct TATA elements, one of which is a target in the $h s p 70$ promoter for ElA regulation. Cell 52: 723-729.

Simon, M.C., R.J. Rooney, T.M. Fisch, N.G. Heintz, and J.R. Nevins. 1990. E1A-dependent trans-activation of the c-fos promoter requires the TATAA sequence. Proc. Natl. Acad. Sci. (in press).

Southern, P.J. and P. Berg. 1982. Transformation of mammaliam cells to antibiotic resistence with a bacterial gene under control of the SV40 early region promoter. $J$. Mol. Appl. Genet. 1: 327-341.

Subramaniam, M., L.J. Schmidt, C.E. Crutchfield III, and M.J. Getz. 1989. Negative regulation of serum-responsive elements. Nature 340: 64-66.

Taylor, M., R. Treisman, N. Garrett, and T. Mohun. 1989. Muscle-specific (CArG) and serum-responsive (SRE) promoter elements are functionally interchangeable in Xenopus embryos and mouse fibroblasts. Development 106: $67-78$.

Treisman, R. 1985. Transient accumulation of c-fos RNA following serum stimulation requires a conserved $5^{\prime}$ element and c-fos 3' sequences. Cell 42: 889-902.

. 1986. Identification of a protein-binding site that mediates transcriptional response of the c-fos gene to serum 
Rivera et al.

factors. Cell 46: $567-574$.

1987. Identification and purification of a polypeptide that binds to the c-fos serum response element. EMBO $J$. 6: $2711-2717$.

Walsh, K. and P. Schimmel. 1988. DNA-binding site for two skeletal actin promoter factors is important for expression in muscle cells. Mol. Cell. Biol. 8: 1800-1802.

Walsh, K. 1989. Cross-binding of factors to functionally different promoter elements in c-fos and skeletal actin genes. Mol. Cell. Biol. 9: 2191-2201.

Wilson, T. and R. Treisman. 1988. Fos C-terminal mutations block down-regulation of c-fos transcription following serum stimulation. EMBO I. 7: 4193-4202. 


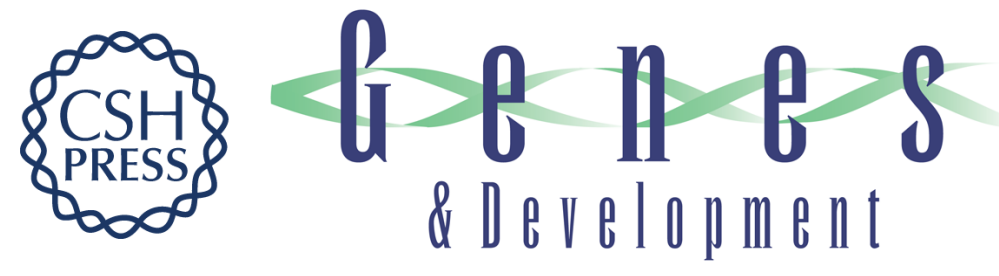

\section{The inner core of the serum response element mediates both the rapid induction and subsequent repression of c-fos transcription following serum stimulation.}

V M Rivera, M Sheng and M E Greenberg

Genes Dev. 1990, 4:

Access the most recent version at doi:10.1101/gad.4.2.255

References This article cites 66 articles, 27 of which can be accessed free at: http://genesdev.cshlp.org/content/4/2/255.full.html\#ref-list-1

License

Email Alerting Service

Receive free email alerts when new articles cite this article - sign up in the box at the top right corner of the article or click here.

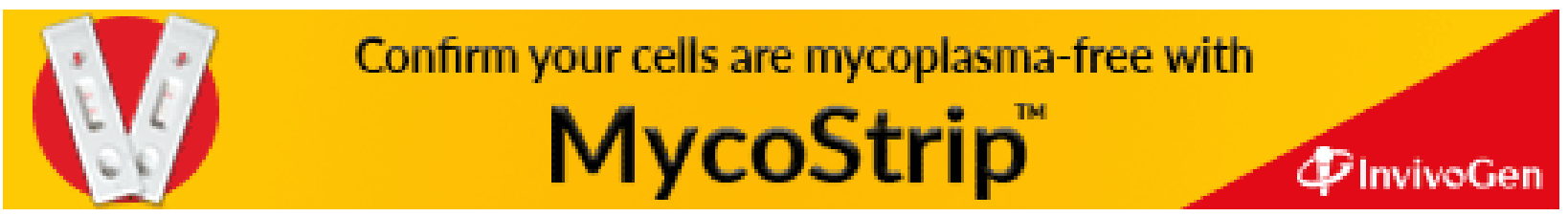

